\title{
Measurements of respiratory illness among construction painters
}

\author{
MARY C WHITE, E L BAKER \\ From the Occupational Health Program, Harvard School of Public Health, Boston, MA, USA
}

\begin{abstract}
The prevalence of different measurements of respiratory illness among construction painters was examined and the relation between respiratory illness and employment as a painter assessed in a cross sectional study of current male members of two local affiliates of a large international union of painters. Respiratory illness was measured by questionnaire and spirometry. Longer employment as a painter was associated with increased prevalence of chronic obstructive disease and an interactive effect was observed for smoking and duration of employment as a painter. Multiple regression analysis showed a significant association between years worked as a painter and a

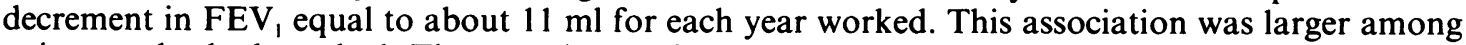
painters who had smoked. The prevalence of chronic bronchitis was significantly associated with increased use of spray application methods.
\end{abstract}

It has been suggested that painters may be at increased risk of respiratory disease due to exposure to solvents and other materials found in paints.' Various potentially toxic materials are used in different types of paints, including epoxy resins, isocyanates, metal pigments, silica fillers, and organic solvents. ${ }^{2}$ The composition of the paint depends on the surface to be covered. Within the construction industry exposures to paint components may reach toxic levels due to high rates of application, the need for more exotic and potentially hazardous coatings, the high volatility of some paint components such as solvents, the use of spray application methods, and the absence of environmental controls. ${ }^{3}$

Relatively little is known about the effects of exposure to paints on the respiratory system. A few surveys of workers exposed to paints have suggested that painters may be at increased risk of chronic obstructive pulmonary disease and other respiratory illnesses.

Selikoff and his colleagues completed pulmonary function tests and administered respiratory symptom questionnaires for 485 current and former painters as part of a larger evaluation of health hazards among members of a painters' union in the United States. ${ }^{4}$ Examinations were conducted among volunteers at the union's annual convention and at two midwestern locations. In response to questionnaire items the prevalence rates were $45 \%$ for irritation of the upper

Accepted 3 August 1987 respiratory tract and conjunctiva, $38 \%$ for irritation of the trachea or bronchus, and $28 \%$ for chronic bronchitis. The reported prevalence rates for respiratory symptoms were higher for painters who worked with epoxy materials. Pulmonary function tests were evaluated for $\mathbf{4 4 8}$ painters and were interpreted by the investigators as indicating restrictive ventilatory impairment in $6 \%$ and obstructive ventilatory impairment in $46 \%$. Chest $x$ ray abnormalities, including parenchymal and pleural changes, were reported among $20 \%$ of the painters examined.

Schacke and Kiwus (unpublished observations) compared measurements of lung function among 108 furniture painters with those from 81 other furniture workers in West Berlin. Both groups were similar in mean age and height. Separate analyses were conducted for smokers and non-smokers. They reported significant differences in $F_{E V}$ and other measurements of lung function which were consistent with increased airway obstruction among painters.

Sabroe and Olsen posted questionnaires to a sample of cabinet makers and carpenters in Denmark to examine the health effects of exposure to lacquers. ${ }^{5}$ Three groups were sampled: present lacquerers, former lacquerers, and those who had never worked with lacquers. The prevalence of cough, phlegm, and shortness of breath when climbing stairs was two to three times higher among present and former lacquerers than among non-lacquerers. Present and former lacquerers also reported higher frequencies of eye and throat irritation. 
In conjunction with a separate study aimed at evaluating the effectiveness of union developed training materials, we had an opportunity to collect information on respiratory symptoms and lung function among a group of construction painters. The purpose of this study was to learn about the prevalence of different measures of respiratory illness among painters and to assess the relation between respiratory illness and employment as a painter. Special attention was paid to the prevalence of chronic obstructive pulmonary disease and exposure to solvent based paints.

\section{Methods}

\section{STUDY POPULATION}

Current members of two local union affiliates of the International Brotherhood of Painters and Allied Trades (IBPAT) were recruited by union employees to participate in a separate study aimed at evaluating the effectiveness of an IBPAT developed training programme. The training programme to be evaluated was designed to reduce exposures at the worksite. All current members of the two local unions were sent a letter from IBPAT explaining the study and offering free health screenings in 1984 and 1985 . Only regular and apprentice IBPAT members who attended the 1984 health screening were included in these analyses.

NON-PARTICIPANTS

A total of 663 regular and apprentice union members were identified in the two local unions; $37 \cdot 1 \%$ participated in the health screening on a voluntary basis. Screening participants and non-participants had similar mean ages $(40.8 v 41.7$ years, $\mathrm{p}=0.42)$ and years since joining the union $(11.4 v 10.8$ years, $p=$ 0.47 ). Information from pension records indicated that screening participants had contributed more mean hours to the pension fund in $1983(1047.3 v 901.7$ hours, $p=0.026$ ) and during the first six months of $1984(584.2 v 454.0$ hours, $p<0.001)$.

\section{QUESTIONNAIRE}

At the time of the health screening, all participants were asked to complete a questionnaire covering their medical and occupational history, with special emphasis on the extent of exposure to paints. Painters were asked the number of years they had painted, the number of weeks they had worked with solvent paints during the past year, and the fraction of time they had used spray application methods, both for the entire time they had been painting and during the past year.

Questions concerning respiratory symptoms and smoking history were based on the American Thoracic Society, Epidemiology Standardisation Project, questionnaire. ${ }^{6}$ Additional questions covered acute irrita- tion to eyes, throat, and nose. Painters were asked if they ever suffered from an itchy, runny, or stuffy nose; if their eyes ever itched or watered and if their throats ever became dry or irritated. If they responded yes they were asked if this happened at least once a week. As one measure of the possible work relatedness of a symptom, painters were also asked whether the symptom got better, worse, or stayed the same during weekends and holidays. Painters who indicated that they usually coughed four or more days a week during the day or at night (not just on getting up in the morning) or brought up phlegm from their chest throughout the day (not just in the morning) were also asked whether these symptoms changed during weekends or holidays.

Following the definition of the American Thoracic Society, ${ }^{7}$ chronic bronchitis was defined as cough with phlegm on most days for as much as three months during the year for at least two years. Pack-years was defined as the average number of cigarettes smoked a day multiplied by the number of years that the painter had smoked divided by 20 .

It has been suggested that psychosocial factors, including job dissatisfaction, may contribute to the reporting of respiratory symptoms among those who appear free of disease on the basis of spirometric measurements. ${ }^{8}$ To control potential confounding by job satisfaction, painters were asked to respond to the question, "How satisfied are you with your job?", using a seven point scale ranging from very satisfied to very dissatisfied.

\section{PULMONARY FUNCTION TESTS}

$\mathrm{FEV}_{1}$, forced vital capacity (FVC), and the mean forced expiratory flow rate during the middle half of the FVC manoeuvre $\left(\mathrm{FEF}_{25-75}\right)$ were measured, using an Eagle-One survey water seal spirometer (WarrenCollins). Tracings were edited by trained technicians to remove "unacceptable" forced expiratory manoeuvres from further analysis. A tracing was considered "unacceptable" if it showed evidence of cough, early termination of expiration, or inconsistent effort. ${ }^{9}$ An attempt was made to obtain at least three acceptable tracings for each participant. Standing height was measured without shoes, rounded to whole inches.

Measurements of the FEV 1 and FVC were considered reproducible if the difference between the largest two values from acceptable tracings did not exceed $5 \%$ of the largest value or $100 \mathrm{ml}$, whichever was the greater. ${ }^{10}$ The largest values for $\mathrm{FEV}_{1}$ and FVC were used as the observed values but they may have been taken from the different manoeuvres. The $\mathrm{FEF}_{25-75}$ was taken from the forced expiratory manoeuvre which had the largest sum of FEV 1 and FVC.

Dockery and coworkers reported that subjects who weighed more than approximately $20 \%$ above or 
below the expected mean weight for their height had lower lung function than expected." To examine the potential confounding effects of excess weight on lung function, self reports of current weight were evaluated against the recommended values for weight by height of the Metropolitan Life Insurance Company for men of medium build. ${ }^{12}$

\section{EXPECTED VALUES FOR PULMONARY FUNCTION TESTS}

Expected values for $\mathrm{FEV}_{1}, \mathrm{FVC}$, and $\mathrm{FEF}_{25-75}$ were derived from the prediction equations of Knudson and coworkers. ${ }^{13}$ These prediction equations include terms for age and standing height but they do not include terms for smoking history because they are based on a non-smoking population. Since these prediction equations were based on a white population, expected values were generated only for whites in the study population. Separate equations were used for men under age 25 and for men aged 25 and over.

Observed values for $\mathrm{FEV}_{1}, \mathrm{FVC}$, and $\mathrm{FEF}_{25-75}$ were considered to be less than expected if the ratio of observed to expected was less than the normal (lower) $95 \%$ percentile values that were published by Knudson et al. The cut off values for $\mathrm{FEV}_{1}$ were 0.812 for men aged under $25,0.791$ for men aged 25 to 40 , and 0.772 for men aged 40 and over. For the FVC, the cut off values were 0.798 for men aged under $25,0.811$ for men aged 25 to 40 , and 0.734 for men aged 40 and over.

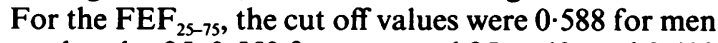
aged under $25,0.553$ for men aged 25 to 40 , and 0.403 for men aged 40 and over.

Painters were classified on the basis of the combined results of these measures of pulmonary function: $\mathrm{FEF}_{25-75}, \mathrm{FEV}_{1}, \mathrm{FVC}$, and $\mathrm{FEV}_{1} / \mathrm{FVC}$. If no ratio value was less than the cut off value the painter was classified as having no evidence of pulmonary disease. If the percentage predicted for $\mathrm{FEF}_{25-75}$ was less than the cut off but all other ratios were not the painter was classified as having possible small airways disease. If the predicted $F E V_{1}$ was less than the cut off or the $F V_{1} / F V C$ ratio was less than $70 \%$, and the predicted FVC was not less than the cut off value, the painter was classified as having possible obstructive pulmonary disease. If only the predicted FVC was less than the cut off the painter was classified as having possible restrictive pulmonary disease. If the predicted ratios


values the painter was classified as having possible mixed obstructive and restrictive pulmonary disease.

Another measure of pulmonary function which was examined was the absolute difference between the observed value of FEV , and the expected value, based on the prediction equation. This measure is not dependent on the use of cut off values.

Two variables that may influence the rate of decrement in lung function are pack-years and years spent as a painter. Both these variables are time dependent and highly correlated with age. Although the prediction equation included a term for age, it is possible that the use of this equation does not eliminate all confunding by age. Therefore, a second set of expected values was generated using a different prediction equation. This second equation included both linear and quadratic terms for age as predictors for FEV ${ }_{1}$ over height squared. The second prediction equation was based on a longitudinal study of the health effects of air pollution and was based on healthy, non-smoking, white men, aged 25 and older. ${ }^{1}$

\section{STATISTICAL ANALYSES}

All analyses were performed on a personal computer with the assistance of SPSS/PC statistical software. ${ }^{14}$ Differences in proportions and odds ratios were tested by chi-square; Fisher's exact test was used if the expected frequency in any cell was less than five. Differences in proportions over several ordered categories were tested for a linear trend by a chi-square with one degree of freedom.

Differences in mean values for continuous variables were tested with a $t$ test; variance estimates were pooled unless the $F$ value for the test for homogeneity of variance was significant at $\mathbf{p}=\mathbf{0 . 0 5}$. A correlation coefficient was used to examine the association between two continuous variables. Multiple linear regression was used to examine differences in mean values over more than one continuous variable. The measure of association was the regression coefficient and the test for significance of the coefficient was a $t$ test. Normality was assessed by examining a normal probability plot of the studentised residuals and equality of variance by a scatter plot of studentised residuals by predicted values.

All $p$ values were two tailed except for chi-squared tests, where the matter does not arise.

\section{Results}

GENERAL CHARACTERISTICS

Of the 246 IBPAT members who participated, 11 were women, nine were drywall tapers who had never worked as painters, and one did not complete the questionnaire. Analyses were restricted to 225 male IBPAT members with a history of employment as a painter.

The mean age of painters included in this study was 41.0 years (range $20-78$ ) and the mean number of years employed as a painter was $18 \cdot 3$ (range $<1-60$ years). The period since last use of solvent paints was less than one month for $74.2 \%$, between one month and one year for $12.9 \%$, and over one year for $12.9 \%$. 
Table 1 Prevalence of transient* and non-transient symptoms by the number of weeks worked with solvent paints in past year

\begin{tabular}{|c|c|c|c|c|c|c|}
\hline & \multicolumn{6}{|c|}{ No of weeks that painter worked with solvent paints } \\
\hline & 0 & $1-13$ & $14-26$ & $27-39$ & $40-52$ & Total \\
\hline No & 29 & 42 & 59 & 33 & 62 & 225 \\
\hline $\begin{array}{l}\text { Transient symptoms: } \\
\text { Nose irritation } \\
\text { Eye irritation } \\
\text { Throat irritation } \\
\text { Frequent cough } \\
\text { Frequent phlegm }\end{array}$ & $\begin{array}{l}6.9 \\
6.9 \\
6.9 \\
0 \\
3.4\end{array}$ & $\begin{array}{c}9.5 \\
19.0 \\
14.3 \\
0 \\
4.8\end{array}$ & $\begin{array}{l}8 \cdot 5 \\
8 \cdot 5 \\
8 \cdot 5 \\
6 \cdot 8 \\
6 \cdot 8\end{array}$ & $\begin{array}{r}15 \cdot 2 \\
12 \cdot 1 \\
18 \cdot 2 \\
9 \cdot 1 \\
6 \cdot 1\end{array}$ & $\begin{array}{c}19 \cdot 4 \dagger \\
24 \cdot 2 \\
9 \cdot 7 \\
11 \cdot 3 \dagger \\
8 \cdot 1\end{array}$ & $\begin{array}{r}12.4 \\
15 \cdot 1 \\
11 \cdot 1 \\
6 \cdot 2 \\
6.2\end{array}$ \\
\hline $\begin{array}{l}\text { Non-transient symptoms: } \\
\text { Nose irritation } \\
\text { Eye irritation } \\
\text { Throat irritation } \\
\text { Frequent cough } \\
\text { Frequent phlegm }\end{array}$ & $\begin{array}{l}24 \cdot 1 \\
13 \cdot 8 \\
20 \cdot 7 \\
10 \cdot 3 \\
17 \cdot 2\end{array}$ & $\begin{array}{l}16.7 \\
19.0 \\
14.3 \\
14.3 \\
16.7\end{array}$ & $\begin{array}{l}22.0 \\
16.9 \\
11.9 \\
18.6 \\
10.2\end{array}$ & $\begin{array}{r}15 \cdot 2 \\
18 \cdot 2 \\
12 \cdot 1 \\
12 \cdot 1 \\
9 \cdot 1\end{array}$ & $\begin{array}{l}21.0 \\
17.7 \\
17.7 \\
12.9 \\
11.3\end{array}$ & $\begin{array}{l}20.0 \\
17.3 \\
15.1 \\
12.9 \\
12.4\end{array}$ \\
\hline
\end{tabular}

"Transient defined as "gets better during weekends or holidays."

$\dagger$ Chi-squared test for a linear trend in proportions was significant at alpha $=0.05$.

\section{SYMPTOMS OF ACUTE IRRITATION}

The prevalences of transient symptoms which improve at weekends were lowest among those who had not worked with solvent paints for at least one week in the past year (table 1). A chi-squared test for a linear trend in proportions indicated increasing prevalence with increasing number of weeks worked with solvents for transient nose irritation $(p=0.038)$, eye irritation $(p=0.075)$, and cough $(p=0.007)$. By contrast, no trend was observed between the prevalence of any symptom that did not improve at weekends and weeks worked with solvents (table 1).

\section{PULMONARY FUNCTION TESTS}

Expected values for measures of pulmonary function were generated only for whites in this study. Of 198 white men, 190 had reproducible values for $\mathrm{FEV}_{1}$ and 186 had reproducible values for both $F E V_{1}$ and FVC. One man did not provide information on smoking history and he was subsequently omitted from further analyses.

Compared with other painters, the 12 painters with non-reproducible values for $\mathrm{FEV}_{1}$ or $\mathrm{FVC}$ were older (mean age $=52.6 v 41.2$ years, $\mathrm{p}=0.005$ ), had worked as a painter for a longer period (mean $=30.5 v 18.7$ years, $p=0.002$ ), and had more pack-years of smoking experience (mean $=38.9 \vee 22.4$ pack-years, $\mathrm{p}$ $=0 \cdot 165$ ).

Of the 185 painters with reproducible values for both FEV, and FVC, two had possible small airways disease, 31 had possible obstructive disease, nine had possible mixed disease, and three had possible restrictive disease (table 2). Thus $43(23.2 \%)$ had evidence of possible obstructive or restrictive pulmonary disease, or both. Of the 14 painters who were classified as having possible obstructive disease on the basis of a
Table 2 Classification of painters by combined results of pulmonary function tests*

\begin{tabular}{|c|c|c|c|}
\hline \multirow[b]{2}{*}{ Classification } & \multicolumn{3}{|c|}{ Last worked with solvents: } \\
\hline & $\begin{array}{l}\leqslant 1 \text { year } \\
(n=160)\end{array}$ & $\begin{array}{l}>1 \text { year } \\
(n=25)\end{array}$ & $\begin{array}{l}\text { Total } \\
(n=185)\end{array}$ \\
\hline $\begin{array}{l}\text { No evidence of abnormality } \\
\text { Possible small airways disease } \\
\text { only }\end{array}$ & $\begin{array}{r}79.4 \% \\
0.6 \%\end{array}$ & $\begin{array}{r}52.0 \% \\
4.0 \%\end{array}$ & $\begin{array}{r}75.7 \% \\
1.1 \%\end{array}$ \\
\hline $\begin{array}{l}\text { Possible obstructive disease } \\
\text { Possible mixed obstructive and } \\
\text { restrictive disease }\end{array}$ & $\begin{array}{r}13 \cdot 8 \% \\
4 \cdot 4 \%\end{array}$ & $\begin{array}{r}36.0 \% \\
8.0 \%\end{array}$ & $\begin{array}{r}16.8 \% \\
4.9 \%\end{array}$ \\
\hline Possible restrictive disease & $1.9 \%$ & $0.0 \%$ & $1.6 \%$ \\
\hline
\end{tabular}

*See text for classification criteria.

low $\mathrm{FEV}_{1} / \mathrm{FVC}$ value, five also had $\mathrm{FEF}_{25-75}$ values that were less than expected. The proportion of painters with either possible obstructive, mixed, or restrictive disease was slightly higher among those who had not worked with solvent paints for over a year.

Among smokers, the prevalence of obstructive pulmonary disease (obstructive and mixed) was generally higher among those with longer exposure to paints, and the difference in prevalences increased with increasing level of pack-years (table 3). The correlation, however, between pack-years and years worked with paints $(r=0.46, p<0.001)$, together with the small numbers in many strata, make it difficult to evaluate the separate contributions of exposure to paint and smoking to obstructive pulmonary disease in this cohort.

Using the difference between the observed and expected value of $F E V_{1}$ as the outcome variable, multivariate regression equations were constructed which included terms for years worked with paints, pack-years, and current smoker (yes or no). Only 
Table 3 Prevalence of obstructive pulmonary disease by spirometry by years worked with paints and pack-years

\begin{tabular}{|c|c|c|c|c|}
\hline \multirow[b]{3}{*}{ Pack-years } & \multicolumn{3}{|c|}{ Prevalence of obstruction } & \multirow{3}{*}{$\begin{array}{l}\text { Difference } \\
\text { in } \\
\text { prevalence }\end{array}$} \\
\hline & \multicolumn{3}{|c|}{ Years worked with paints } & \\
\hline & $>20$ & $\leqslant 20$ & Total & \\
\hline None & $\stackrel{6 \cdot 7}{(n=15)}$ & $\begin{array}{l}10 \cdot 0 \\
(n=20)\end{array}$ & $\stackrel{8 \cdot 6}{(n=35)}$ & $-3 \cdot 3$ \\
\hline$<20$ & $\begin{array}{l}18 \cdot 8 \\
(\mathrm{n}=16)\end{array}$ & $\begin{array}{c}8 \cdot 0 \\
(n=50)\end{array}$ & $\begin{array}{l}10 \cdot 6 \\
(n=66)\end{array}$ & $10 \cdot 8$ \\
\hline $20-39 \cdot 9$ & $\begin{array}{l}26 \cdot 3 \\
(n=19)\end{array}$ & $\begin{array}{l}12.5 \\
(\mathrm{n}=32)\end{array}$ & $\begin{array}{l}17 \cdot 6 \\
(n=51)\end{array}$ & $13 \cdot 8$ \\
\hline$\geqslant 40$ & $\begin{array}{l}67 \cdot 9 \\
(n=28)\end{array}$ & $\begin{array}{l}40 \cdot 0 \\
(n=5)\end{array}$ & $\begin{array}{l}63 \cdot 6 \\
(\mathrm{n}=33)\end{array}$ & $27 \cdot 9$ \\
\hline
\end{tabular}

painters who had reproducible values for FEV, were included in these analyses.

The term for current smoker was retained in all models, even if its coefficient was not statistically significant, because of the importance of cigarette smoking as a potential confounder. Omission of this term, which had a negative coefficient, resulted in a slight increase in magnitude of the coefficient for packyears and a slight decrease in the coefficient for paintyears.

The regression coefficient for the paint term represents the mean difference in $F E V_{1}$ for each year of employment as a painter (table 4). For all painters, this coefficient was equivalent to a mean decrement of $11 \mathrm{ml}$ in $\mathrm{FEV}_{1}$ for each year of exposure to paint. The adjusted $\mathbf{R}$ square for the multiple regression model was 0.22 . An examination of the residuals did not indicate that the assumptions of normality or equality of variance had been violated.

Separate analyses were run for painters who had never smoked and for painters who were either current or former smokers. The coefficient for paint years for those who had smoked was about three times as large as that for those who had never smoked, indicating a possible interactive effect between smoking and exposure to paint.

A dichotomous term was added to the model, indicating whether the painter had not worked with solvent paints for more than a year. The inclusion of this term (coefficient $=-0.02321, p=0.23$ ) in the model had little effect on the overall fit of the model or on the coefficients for either pack-years or paint-years.

Painters had indicated the proportion of time they had used spray application methods. This term was added to the model which included terms for packyears, paint-years, and current smoker. The coefficient for this term was positive but not statistically stable (coefficient $=0.206, p=0.25$ ), and its inclusion in the model did not improve the overall fit of the model or influence the coefficients of other terms.
Table 4 Regression coefficients* for years worked as a painter and pack-years with difference in FEV (observedexpected) as the outcome

\begin{tabular}{|c|c|c|c|c|c|}
\hline \multirow[b]{2}{*}{ Population } & \multirow[b]{2}{*}{ No } & \multicolumn{2}{|c|}{ Years as painter } & \multicolumn{2}{|c|}{ Pack-years } \\
\hline & & $b l$ & $p$ & $b 2$ & $p$ \\
\hline $\begin{array}{l}\text { Expected based o } \\
\text { All } \\
\text { Ever smoke } \\
\text { Never smoke } \\
\text { Age } \geqslant 25 \mathrm{y}\end{array}$ & $\begin{array}{c}\text { Knuc } \\
189 \\
154 \\
35 \\
177\end{array}$ & $\begin{array}{l}\text { dson et al }{ }^{13} \text { : } \\
-0.0114 \\
-0.0129 \\
-0.0044 \\
-0.0110\end{array}$ & $\begin{array}{l}0.005 \\
0.005 \\
0.64 \\
0.010\end{array}$ & $\begin{array}{l}-0.0074 \\
-0.0082 \\
-0.0073\end{array}$ & $\begin{array}{l}0.0002 \\
0.0002 \\
\\
0.0004\end{array}$ \\
\hline $\begin{array}{c}\text { Expected based } \\
\text { Age } \geqslant 25 y\end{array}$ & $\begin{array}{l}\text { Dock } \\
177\end{array}$ & $\begin{array}{l}\text { keryet al }{ }^{\prime \prime}: \\
-0.0119 \dagger\end{array}$ & 0.003 & $-0.0067 \dagger$ & 0.0006 \\
\hline
\end{tabular}

*Typical regression equation: $F E V$, difference $=a+b l$ (years worked as a painter) + b2 (pack-years) + b3 (current smoker), where FEV $_{1}$ difference $=\left(\left(\right.\right.$ observed FEV $\left._{1}\right)$ - (expected FEV, using prediction equation)).

+Coefficients are for a painter $1.73 \mathrm{~m}$ in height.

Table 5 Prevalence of chronic bronchitis by years worked with paints and pack-years

\begin{tabular}{llllc}
\hline & \multicolumn{2}{l}{ Prevalence of chronic bronchitis } \\
\cline { 2 - 5 } Pack-years & \multicolumn{2}{c}{ Years worked with paints } & $\begin{array}{c}\text { Difference } \\
\text { in } \\
\text { prevalence }\end{array}$ \\
\cline { 2 - 5 } None & $\begin{array}{l}11 \cdot 8 \\
(\mathrm{n}=17)\end{array}$ & $\begin{array}{l}10 \cdot 7 \\
(\mathrm{n}=28)\end{array}$ & $\begin{array}{l}11 \cdot 1 \\
(\mathrm{n}=45)\end{array}$ & $1 \cdot 1$ \\
$<20$ & $\begin{array}{l}20 \cdot 0 \\
(\mathrm{n}=20)\end{array}$ & $\begin{array}{l}17 \cdot 5 \\
(\mathrm{n}=63)\end{array}$ & $\begin{array}{l}18 \cdot 1 \\
(\mathrm{n}=83)\end{array}$ \\
$20-39 \cdot 9$ & $\begin{array}{l}20 \cdot 0 \\
(\mathrm{n}=20)\end{array}$ & $\begin{array}{l}32 \cdot 4 \\
(\mathrm{n}=37)\end{array}$ & $\begin{array}{l}28 \cdot 1 \\
(\mathrm{n}=57)\end{array}$ & $-12 \cdot 4$ \\
240 & $\begin{array}{l}54 \cdot 5 \\
(\mathrm{n}=33)\end{array}$ & $\begin{array}{l}33 \cdot 3 \\
(\mathrm{n}=6)\end{array}$ & $\begin{array}{l}51 \cdot 3 \\
(\mathrm{n}=39)\end{array}$ & $21 \cdot 2$ \\
\hline
\end{tabular}

Among painters who had reproducible values for $\mathrm{FEV}_{1}, 32 \cdot 3 \%$ were more than $20 \%$ above the recommended weight for their height and $6.3 \%$ did not provide values for weight. To control for the potential confounding by weight, a regression analysis was performed on only those painters whose weight was not greater than $20 \%$ above the recommended value. The coefficient for paint-years $(-0.0152, p=0.007)$ was slightly larger and the coefficient for pack-years $(-0.0053, p=0.057)$ slightly smaller for these painters than for the entire population.

Eight painters had values for pack-years that exceeded 80. Because of the potential for error in the estimates of pack-years and the influence such individuals could have on the regression coefficient for pack-years, an analysis was performed omitting these eight. The regression coefficient for pack-years $(-0.0118, p<0.0001)$ was slightly greater and the coefficient for paint-years $(-0.0089, p=0.027)$ slightly smaller when those with the highest values for pack-years were omitted. 
Table 6 Prevalence of chronic bronchitis by use of spray application methods*

\begin{tabular}{|c|c|c|c|c|c|c|c|}
\hline & \multicolumn{7}{|c|}{ Proportion of time spent spraying: } \\
\hline & Never & $<1 / 4$ & $1 / 4-1 / 2$ & $1 / 2-3 / 4$ & $>3 / 4$ & Total & \\
\hline $\begin{array}{l}\text { No } \\
\% \text { Chronic bronchitis } \\
\% \text { Shortness of breath } \\
\text { Mean age (SD) } \\
\text { Mean pack-years (SD) } \\
\text { Mean paint-years (SD) }\end{array}$ & $\begin{array}{l}15 \\
0 \cdot 0 \\
0.0 \\
42.9(15 \cdot 3) \\
18 \cdot 2(15 \cdot 9) \\
17 \cdot 1(14 \cdot 5)\end{array}$ & $\begin{array}{l}102 \\
15.7 \\
12.7 \\
41.3(12.8) \\
19.9(22.9) \\
18.5(12.2)\end{array}$ & $\begin{array}{l}53 \\
39 \cdot 6 \\
32 \cdot 1 \\
42 \cdot 8(14 \cdot 5) \\
22 \cdot 6(28 \cdot 1) \\
20 \cdot 7(13 \cdot 8)\end{array}$ & $\begin{array}{l}31 \\
29 \cdot 0 \\
19 \cdot 4 \\
40 \cdot 6(12 \cdot 7) \\
26 \cdot 7(26 \cdot 5) \\
17 \cdot 8(11 \cdot 8)\end{array}$ & $\begin{array}{l}23 \\
39 \cdot 1 \\
17 \cdot 4 \\
33 \cdot 0(9 \cdot 6) \\
21.9(26 \cdot 1) \\
12.7(9 \cdot 3)\end{array}$ & $\begin{array}{l}224 \\
24 \cdot 6 \dagger \\
17 \cdot 9 \\
40 \cdot 8 \\
21 \cdot 6 \\
18 \cdot 3\end{array}$ & $\begin{array}{l}(13 \cdot 3) \\
(24 \cdot 6) \\
(12 \cdot 5)\end{array}$ \\
\hline
\end{tabular}

"Painters were asked, "During the time you have painted, what fraction of the time have you used spray application methods?"

†Chi-squared test for a linear trend in proportions was significant at alpha $=0.05$.

Table 7 Reduction in time spent spraying during the past year by presence of chronic bronchitis and by per cent predicted value for $F E V_{1}^{*}$

\begin{tabular}{|c|c|c|c|}
\hline & No & $\begin{array}{l}\text { Proportion } \\
\text { who sprayed } \\
\text { less past year }\end{array}$ & \\
\hline $\begin{array}{l}\text { No chronic bronchitis } \\
\text { Chronic bronchitis }\end{array}$ & $\begin{array}{r}149 \\
47\end{array}$ & $\begin{array}{l}24 \cdot 8 \% \\
36 \cdot 2 \%\end{array}$ & $p=0.13$ \\
\hline Total & 198 & & \\
\hline $\begin{array}{l}\text { Per cent predicted value } \\
>90 \% \\
>70-90 \% \\
\leqslant 70 \%\end{array}$ & $\begin{array}{l}\text { for } \mathrm{FEV}_{1} \text { : } \\
110 \\
42 \\
12\end{array}$ & $\begin{array}{l}21 \cdot 8 \% \\
35 \cdot 7 \% \\
66 \cdot 7 \%\end{array}$ & $p=0.0026$ \\
\hline Total & 164 & & \\
\hline
\end{tabular}

*Per cent predicted $\mathrm{FEV}_{1}=$ (observed value for $\mathrm{FEV}$ ) $/\left(\mathrm{FEV}_{1}\right.$ value from prediction equation of Knudson $e t a l)$ ), and was available for whites only.

As an alternative method to control for the effects of age, a separate regression equation for painters aged 25 and older was run using the expected values from Dockery et al. ${ }^{\prime \prime}$ Because the prediction equation was based on $\mathrm{FEV}_{1}$ divided by height squared, the difference in observed minus expected $\mathrm{FEV}_{\text {, }}$ was also divided by height squared. Coefficients are presented for a painter $1.73 \mathrm{~m}\left(5^{\prime} 8^{\prime \prime}\right)$ in height in table 4 . The coefficients for years worked with solvents and packyears are similar to those derived from the difference between the observed and expected values based on Knudson et al for painters aged 25 and older. ${ }^{13}$

\section{SYMPTOMS OF CHRONIC RESPIRATORY \\ IMPAIRMENT}

Overall, the prevalence of chronic bronchitis among these painters was $24.9 \%$ and the prevalence of shortness of breath, classified by increasing severity, was $10.2 \%$ for shortness of breath when walking up one flight of stairs, $4.4 \%$ for having to walk slower than people of the same age because of shortness of breath, and $3.6 \%$ for having to stop because of shortness of breath when walking on level ground at own pace. The presence of shortness of breath of any severity was strongly associated with the presence of chronic bronchitis (odds ratio $=6.7, \mathrm{p}<0.0001$ ).

Among painters who had evidence of possible obstructive or mixed pulmonary disease, the prevalence of chronic bronchitis was $51 \cdot 3 \%$. None of the three painters with evidence of possible restrictive disease reported chronic bronchitis although one of the two painters with evidence of possible small airways disease did. Of the painters who had no evidence of disease from pulmonary function tests, the prevalence of chronic bronchitis was $21 \%$.

Among painters who had no evidence of impairment from spirometric measurements, the prevalence of chronic bronchitis was compared by level of job satisfaction. Overall, most $(70 \cdot 3 \%)$ expressed satisfaction with their job. A higher prevalence of chronic bronchitis was reported among those who expressed dissatisfaction with their job, and a test for a linear trend in proportion by decreasing level of job satisfaction was positive and statistically significant (chisquare $=9.69, \mathrm{p}=0.002$ ). The proportion of painters, however, who were current smokers also increased linearly with decreasing level of job satisfaction (chi-square $=3.88, p=0.049$ ). Among painters who were current smokers, no clear association between job satisfaction and the prevalence of chronic bronchitis was observed (chi-square $=1.53, p=0.22$ ).

The prevalence of chronic bronchitis was highest among painters with the greatest pack-years of smoking experience (table 5). The association between the prevalence of chronic bronchitis and longer exposure to paints, however, was not consistent across different strata of pack-years (table 5).

Greater use of spray application methods was positively associated with higher prevalence of chronic bronchitis (chi-squared $=11 \cdot 22, \mathrm{p}=0.0008$ ) but not with shortness of breath of any severity (chi-squared $=2 \cdot 27, p=0.13$ ) (table 6). When the analysis was restricted to current smokers, a positive association between spray painting and chronic bronchitis was still observed (chi-squared $=5 \cdot 36, p=0.02$ ). Those 
who spent most of their time using spray application methods were, on average, younger and had spent fewer years working as a painter.

Indications of respiratory illness were associated with reduced use of spray application methods (table 7). Analyses were restricted to painters who had worked with solvent paints during the past year. Painters with chronic bronchitis were more likely to use spray application methods less during the past year than for the entire time they had painted, although this difference was not statistically significant. In addition, those with greater impairment of lung function, as measured as the per cent predicted value for $\mathrm{FEV}_{1}$, were more likely to have reduced their use of spray application methods.

\section{Discussion}

The results of this study indicated several associations between exposure to paints and measures of respiratory illness. The prevalence of some symptoms which improved during weekends or holidays, particularly nose irritation and frequent cough, increased with increasing number of weeks worked with solvent paints during the past year. The difference in the observed minus expected value of $F E V_{1}$ was negatively associated with the number of years worked with paints. Painters who reported symptoms of chronic bronchitis were more likely to have spent a greater portion of their time using spray application methods. In addition, an indication of an interactive effect between smoking and pulmonary function was observed.

Two different measures were used to assess obstructive disease in this cohort, spirometric measures of pulmonary function and questionnaires. Spirometry is viewed by many as the more objective measure but in this instance it suffers from reliance on potentially non-comparable populations to generate expected values and dependence on cut-off values to define disease. Self reports of symptoms may be more subjective but the symptoms of chronic bronchitis may be a more specific measure of the functional abnormality of interest.

Within this cohort obstructive disease measured by spirometry and chronic bronchitis measured by questionnaires did not always occur together. It has been suggested that psychosocial factors, such as low job satisfaction, may lead to overreporting of respiratory symptoms. ${ }^{15}$ In this study the association between job satisfaction and chronic bronchitis was confounded by current smoking status. Among current smokers with normal pulmonary function test results, no clear association was observed between job satisfaction and the presence of chronic bronchitis. Among these painters, chronic bronchitis in the absence of abnor- mal pulmonary function tests may be due to physiological rather than psychosocial factors.

Obstructive disease as identified from spirometric measures was associated with years of exposure to paint but not with the fraction of time spent spraying. On the other hand, chronic bronchitis as measured by questionnaires was associated with the fraction of time spent spraying but not with years of paint exposure. One explanation for these differences may be that chronic bronchitis and impairment of pulmonary function may reflect slightly different entities with a different aetiology. Chronic bronchitis may be associated more strongly with the high levels of exposures to paint products that are generated during spray painting whereas impairment in pulmonary function may be related more strongly with chronic, long term exposures to paint products.

Another explanation for these different observations could be different selection factors for spray painting compared with other types of painting. Painters who had spent most of their time spraying were younger than other painters. In addition, impairment in lung function, as measured by the per cent predicted value for $F E V_{1}$ was more strongly associated with a reduced use of spray application methods than was the presence of chronic bronchitis. Thus if painters switched from spray painting to other types of painting after they developed respiratory disease this self selection away from spraying would act as a negative confounder for a cross sectional study of the effects of respiratory disease and spraying. The influence of this negative confounder may have been stronger for measures of pulmonary function than for measures of chronic bronchitis.

The presence of other uncontrolled confounders could have influenced the study results. Although measures of smoking were considered in the analyses, the presence of residual confounding by smoking cannot be ruled out. Pack-years and paint-years were highly correlated, although both were found to be significant predictors of the FEV , difference in multiple regression models that included terms for both variables. If the coefficient for pack-years was substantially underestimated then the coefficient for paintyears could be spuriously high.

Speizer and colleagues reported an irreversible loss of $\mathrm{FEV}_{1}$ among a random sample of men which could be described by a simple linear function of packyears. ${ }^{16}$ In their model, which included linear and quadratic terms for age and an indicator term for current smoker, the estimated effect of pack-years (for a man $1.73 \mathrm{~m}$ tall) was about -0.008 , or a decrement of $8 \mathrm{ml}$ for each pack-year smoked. This estimate of effect for pack-years was similar to the coefficients for pack-years in the multiple regression equations in this study. Thus the term for pack-years in the model 
which included paint-years may not have substantially underestimated the contribution of pack-years to the decrement in $\mathrm{FEV}_{1}$.

The use of different prediction equations to generate expected values for FEV 1 appeared to have had little effect on the measure of association between FEV and paint-years. The two prediction equations were based on different populations and used different mathematical models to control for age and height. Nevertheless, the resulting measures of association between years worked as a painter and decrement in FEV using the two different prediction equations were similar.

The exclusion of subjects with non-reproducible values for $\mathrm{FEV}_{1}$ has been shown to introduce the potential for selection bias in both longitudinal and cross sectional studies. ${ }^{17} 18$ The direction of the potential bias is to underestimate the measure of association. In this cohort painters with non-reproducible values for both $F E V_{1}$ and $F V C$ were found to be older, to have more pack-years of smoking experience, and to have worked as a painter for a longer period. Thus they might be expected also to have higher rates of respiratory illness. Only eight painters, however, were excluded from the regression analyses due to nonreproducible values for $\mathrm{FEV}_{1}$, a smaller percentage than that reported by Eisen and her colleagues in other studies. As a practical matter, the magnitude of the potential bias introduced by their exclusion would not be expected to be large.

Participation among eligible union members was less than $40 \%$. The potential for bias due to self selection into the study cannot be discounted. Because volunteers are a non-random sample of all eligible painters, estimates of prevalences must be viewed with caution. Participants in the study were similar in mean age and years since joining the union but had contributed more hours to the pension fund during the previous 18 months. Presumably, this indicates that they had worked more and suggests that inability to work was not an important reason for taking part in the study.

Of potentially greater concern is the bias that may have been introduced into measures of association between exposure to paint and indications of respiratory illness. Selection bias could be responsible for the measures of association that were observed if painters selected themselves on the basis of both exposure to paint and respiratory illness. Unfortunately, no information on either factor is available for those who did not take part in the study. It is known, however, that a large number of eligible union members had never been contacted by the union. In addition, promotional materials distributed by the union to encourage participation made reference to the hazards of painting in general but made no specific reference to respiratory illness or to tests of pulmonary function.

This was a study of regular and apprentice union members. Although some union members no longer painted, most retired and former painters were not represented in this cohort. It appeared that respiratory impairment was more prevalent among painters who had not worked with solvent paints for more than a year. Thus prevalence measures based only on current union members could underestimate the true prevalences among all who have worked as painters.

Comparatively little is known about the experiences of workers in the construction industry. Longitudinal studies are preferable to cross sectional studies for evaluating long term exposures and respiratory illness. Workers in construction, however, are employed by multiple employers on varying worksites, work odd shifts, and must go to where the work is. For these reasons, construction workers are hard to recruit and even harder to follow up over time. The per cent of participation among eligible workers in this study was actually higher than that reported in other studies of construction workers. ${ }^{19} 20$

The shortcomings of cross sectional studies are compounded by the crude measures of exposures. Industrial hygiene measurements are preferable but may not be very informative, since the composition of paint materials and working conditions change from one worksite to another.

In terms of health risks more may be learned from an examination of toxicity studies of specific paint components than could ever be shown from epidemiological studies of construction painters. Perhaps the most valuable contribution of epidemiological studies is the measure of risks related to the failure to apply knowledge about toxicity to reduce health hazards. The results of this study suggest that greater attention should be paid to the identification of respiratory toxins present in paints and to the reduction of exposures to these toxins.

Marilyn Larson, director of the Occupational Safety and Health Project at the International Brotherhood of Painters and Allied Trades, generously provided access to the participants of the IBPAT Painter Cancer-Risk Reduction Training Evaluation Project for this study. Drs John Bailar, Ellen Eisen, and Richard Monson provided thoughtful comment and advice. We thank the members of IBPAT Locals 49 and 318 for their cooperation in participating in this study and the staff and trainees of the Harvard Occupational Health Program for their help in collecting data.

This study was supported in part by PHS grant Nos 1 RO3 CA41131-01 and 1 RO1 CA34919-01 from the 
National Cancer Institute, DHHS. During this investigation, Dr White was supported by a National Institute of Environmental Health Sciences National Research Service Award, No 5T32 ESO7069 from the Harvard School of Public Health.

Requests for reprints to: Dr E L Baker, National Institute for Occupational Safety and Health, Centers for Disease Control, Atlanta, GA, 30333, USA.

\section{References}

1 Kilburn KH. Respiratory symptoms due to paint exposure. In: Englund A, Ringen K, Mehlman MA, eds. Occupational health hazards of solvents. Princeton: Princeton Scientific Publishers Inc, 1982:153-6. (Advances in modern environmental toxicology; vol II).

2 Burgess WA. Recognition of health hazards in industry. New York: John Wiley \& Sons, 1981:101-4.

3 Ringen $\mathrm{K}$. Health hazards among painters. In: Englund A, Ringen K, Mehlman MA, eds. Occupational health hazards of solvents. Princeton: Princeton Scientific Publishers Inc, 1982:111-38. (Advances in modern environmental toxicology, vol II).

4 Selikoff IJ. Investigations of health hazards in the painting trades. New York: Environmental Sciences Laboratory, Mount Sinai School of Medicine, 1975. (Report to the National Institute for Occupational Safety and Health, contract CDC 99-74-91.)

5 Sabroe S, Olsen J. Health complaints and work conditions among lacquerers in the Danish furniture industry. Scand J Soc Med 1979;7:97-104.

6 Ferris BG. Epidemiology standardization project. Am Rev Respir Dis 1978;118:7-35.

7 American Thoracic Society Task Group on Screening for Respiratory Disease in Occupational Settings. Surveillance for respiratory hazards in the occupational setting. Am Rev Respir Dis 1982;126:952-6.

8 Wright DD, Kane RL, Olsen DM, Smith TJ. The effects of selected psychosocial factors on the self-reporting of pulmonary symptoms. J Chronic Dis 1977;30:195-206.

9 Horvath EP, ed. Manual of spirometry in occupational medicine. Cincinnati: National Institute for Occupational Safety and Health, 1981:13-6.

10 Snowbird Workshop on Standardization of Spirometry. ATS statement. Am Rev Respir Dis 1979;119:831-8.

11 Dockery DW, Ware JH, Ferris BG, et al. Distribution of forced expiratory volume in one second and forced vital capacity in healthy, white, adult never-smokers in six US cities. Am Rev Respir Dis 1985;131:511-20.

12 Health and Safety Education Division, Metropolitan Life Insurance Company. 1983 Metropolitan height and weight tables. New York: Metropolitan Life Insurance Company, 1983.

13 Knudson RJ, Lebowitz MD, Holberg CJ, Burrows B. Changes in the normal maximal expiratory flow-volume curve with growth and aging. Am Rev Respir Dis 1983;127:725-34.

14 SPSS Inc, Norusis MJ. SPSS/PC for the IBM PC/XT. Chicago: SPSS Inc, 1984.

15 Morgan WP. Psychometric correlates of respiration: a review. Am Ind Hyg Assoc J 1983;44:677-84.

16 Speizer FE, Dockery DW, Ferris BG, Ware JH, Louis T. A simple model for the loss of pulmonary function associated with cigarette smoking. Am Rev Respir Dis 1985;131(suppl):A177.

17 Eisen EA, Wegman DH, Louis T. Effects of selection in a prospective study of forced expiratory volume in Vermont granite workers. Am Rev Respir Dis 1983;128:587-91.

18 Eisen EA, Oliver LC, Christiani DC, Robins JM, Wegman DH Effects of spirometry standards in two occupational cohorts. Am Rev Respir Dis 1985;132:120-4.

19 Sprince NL, Oliver C, McLoud TC. Asbestos-related disease in plumbers and pipefitters employed in building construction. $J$ Occup Med 1985;10:771-5.

20 Baker EL, Dagg T, Greene RE. Asbestos-associated illness in the construction trades. I. The significance of pleural disease among sheet metal workers. J Occup Med 1985:27:483-9. 